\title{
Synthesis of a Cementitious Material Nanocement Using Bottom-Up Nanotechnology Concept: An Alternative Approach to Avoid $\mathrm{CO}_{2}$ Emission during Production of Cement
}

\author{
Byung Wan Jo, Sumit Chakraborty, and Kwang Won Yoon \\ Department of Civil and Environmental Engineering, Hanyang University, Seoul 133791, Republic of Korea \\ Correspondence should be addressed to Byung Wan Jo; joycon@hanmail.net
}

Received 2 May 2014; Revised 18 July 2014; Accepted 26 July 2014; Published 11 September 2014

Academic Editor: Gaurav Mago

Copyright (c) 2014 Byung Wan Jo et al. This is an open access article distributed under the Creative Commons Attribution License, which permits unrestricted use, distribution, and reproduction in any medium, provided the original work is properly cited.

The world's increasing need is to develop smart and sustainable construction material, which will generate minimal climate changing gas during their production. The bottom-up nanotechnology has established itself as a promising alternative technique for the production of the cementitious material. The present investigation deals with the chemical synthesis of cementitious material using nanosilica, sodium aluminate, sodium hydroxide, and calcium nitrate as reacting phases. The characteristic properties of the chemically synthesized nanocement were verified by the chemical composition analysis, setting time measurement, particle size distribution, fineness analysis, and SEM and XRD analyses. Finally, the performance of the nanocement was ensured by the fabrication and characterization of the nanocement based mortar. Comparing the results with the commercially available cement product, it is demonstrated that the chemically synthesized nanocement not only shows better physical and mechanical performance, but also brings several encouraging impacts to the society, including the reduction of $\mathrm{CO}_{2}$ emission and the development of sustainable construction material. A plausible reaction scheme has been proposed to explain the synthesis and the overall performances of the nanocement.

\section{Introduction}

The modern civil infrastructures undeniably depend on the cement based material. More than ever before, the world's increasing need for the development of the new infrastructure demands the construction of efficient, sustainable, and durable building materials, generating minimal climate changing gas during their production. Based on the worldwide screening report, it is apparent that the Portland cement is the most common and widely used construction material and its current production is estimated to be $\sim 2$ billion tons per year. Reviewing the literature, it is anticipated that the abundant resource of the oxide composition $\left(\mathrm{SiO}_{2}, \mathrm{CaO}\right.$, $\mathrm{Al}_{2} \mathrm{O}_{3}$, and $\mathrm{Fe}_{2} \mathrm{O}_{3}$ ) present in the cement is the earth's crust $(\sim 90 \%)$. The earth's crust is used as a primary raw material for the production of cement [1]. Additionally, it is reported that during the production of the 1 ton of cement, $\sim 700 \mathrm{~kg}-800 \mathrm{~kg}$ of $\mathrm{CO}_{2}$ is liberated [2]. The $\mathrm{CO}_{2}$ is the primary component of the greenhouse gases and causes global warming and environmental pollution. Therefore, an immediate practical plan is required to reduce the $\mathrm{CO}_{2}$ emission. Accordingly, it is essential to produce cement using an alternative pathway other than clinkering method. In this regard, the nanotechnology would be the encouraging practice. Although, the properties of concrete have been well established at a macrostructural level; however, the understanding of the properties of micro/nanoscale level is yet to be investigated [3-5]. Recently, due to the availability of the modern characterization techniques, it is possible to characterize the cement concrete at nanoscale level $[6,7]$. Thus, it is ascertained that the nanotechnology is the unique scheme of science, able to change our vision, expectations, and amenities to control the material world. The technological revolution towards nanoscale level has propensity to improve the quality of the products and services. Therefore, the encouraging impacts of the nanotechnology will definitely affect the field of building and construction materials. Hence, in the present scenario, the researchers have been motivated to develop high 
TABLE 1: Effect of different nanomaterials on the performances of the cement composite.

\begin{tabular}{|c|c|c|c|c|}
\hline Primary material & Additives/procedure & Particle Size & Effect/performance & Reference \\
\hline Portland cement & $\begin{array}{l}\text { Nanosize ingredients such } \\
\text { as alumina, silica particles, } \\
\text { and carbon nanotubes were } \\
\text { added }\end{array}$ & $<500 \mathrm{~nm}$ & $\begin{array}{l}\text { Nanocement can create new materials, } \\
\text { devices, and systems at the molecular, } \\
\text { nano- and microlevel }\end{array}$ & [3] \\
\hline Portland cement & $\begin{array}{l}\text { Nano- }-\mathrm{SiO}_{2}, \text { nano- }-\mathrm{TiO}_{2} \\
\text { nano- } \mathrm{Al}_{2} \mathrm{O}_{3}, \text { nano- }-\mathrm{Fe}_{2} \mathrm{O}_{3} \text {, } \\
\text { and nanotube/nanofibres } \\
\text { were added }\end{array}$ & $\sim 20 \mathrm{~nm}$ and $100 \mathrm{~nm}$ & $\begin{array}{l}\text { Can produce concrete with superior } \\
\text { mechanical properties as well as } \\
\text { improved durability }\end{array}$ & {$[4]$} \\
\hline Portland cement & $\begin{array}{l}\text { Single wall and multiwall } \\
\text { carbon nanotubes were } \\
\text { added }\end{array}$ & - & $\begin{array}{l}\text { Cement materials showed superior } \\
\text { mechanical, electrical, and thermal } \\
\text { properties }\end{array}$ & [8] \\
\hline $\begin{array}{l}\text { Ordinary Portland } \\
\text { cement }\end{array}$ & $\begin{array}{l}\text { Spherical nanoparticle } \\
\text { nano- } \mathrm{SiO}_{2} \text {, nano- } \mathrm{Fe}_{2} \mathrm{O}_{3} \text {, } \\
\text { and multiwall carbon } \\
\text { nanotubes were added }\end{array}$ & $1-100 \mathrm{~nm}$ & $\begin{array}{l}\text { Significant improvement in } \\
\text { compressive strength as well as Young's } \\
\text { modulus and hardness of the concrete }\end{array}$ & [9] \\
\hline Portland cement & $\begin{array}{l}\text { Spherical nano- } \mathrm{Fe}_{2} \mathrm{O}_{3} \text { and } \\
\text { nano- } \mathrm{SiO}_{2} \text { were added }\end{array}$ & $15 \mathrm{~nm}$ & $\begin{array}{l}\text { Mortar showed higher compressive } \\
\text { strength as well as flexural strength }\end{array}$ & {$[16]$} \\
\hline $\begin{array}{l}\text { Nano- } \mathrm{SiO}_{2}, \\
\text { nano- } \mathrm{NaAlO}_{2} \text {, and } \\
\text { nano- } \mathrm{Ca}\left(\mathrm{NO}_{3}\right)_{2}\end{array}$ & $\begin{array}{l}\text { Using the hydrothermal } \\
\text { method, a new type of } \\
\text { cement material is } \\
\text { produced }\end{array}$ & $167 \mathrm{~nm}$ & $\begin{array}{l}\text { A new cementitious material is } \\
\text { produced using pozzolanic material } \\
\text { infused with hydrated alumina which } \\
\text { avoids } \mathrm{CO}_{2} \text { emission, able to control } \\
\text { mechanical performance of the mortar }\end{array}$ & Present work \\
\hline
\end{tabular}

performance, smart and sustainable construction materials by the tuning of the existing processes together in combination with the nanotechnology $[4,8,9]$. At the outset, it was anticipated that the mechanical performances and the durability of concrete could be improved by reducing the overall porosity of the concrete [4]. It can only be possible if the capillary pores of the cement paste are reduced or the diffusion of the pore solution is restricted by the assimilation of some additives to a similar range of capillary pore sizes $[4,9,10]$. Thus, the bottom-up nanoengineered construction process is used to reduce nanocapillary pores of cement paste $[4,8]$. Accordingly, the process is a very successful and promising one, which encompasses the structure at the nanoscale level to develop multifunctional cement composites with superior mechanical performance and durability $[4,9,10]$. Perhaps, the nanoengineered construction process is mainly based on the incorporation of nanoscale materials such as spherical nanomaterial (namely, nano- $\mathrm{SiO}_{2}$, nano$\mathrm{TiO}_{2}$, nano- $\mathrm{Al}_{2} \mathrm{O}_{3}$, nano- $\mathrm{Fe}_{2} \mathrm{O}_{3}$, etc.), nanofiber (namely, carbon nanotube (CNT) and carbon nanofibers (CNF)), and nanoclay into cement system during mixing of cement and aggregate to produce concrete $[4,7-10]$. In view of that, the nanoengineered process potentially brings a range of novel properties such as high ductility, self-healing, self-crack controlling ability, low electrical resistivity, and self-sensing capabilities [11]. In addition to the nanoparticle incorporation in concrete system, modification of the aggregate surface using nanoporous thin film to produce nanoengineered construction material is also reported elsewhere in order to improve the interfacial transition zone (ITZ) in between aggregate and cement paste [12-16]. Moreover, in a previous research, we have demonstrated that the chemical synthesis of a cementitious material using noncarbon based raw material [17]. Table 1 summarizes the effect of different nanomaterials and procedures on the performances of the nanoengineered concrete.

Reviewing the literature, it is prophesied that the incorporation of the external nanomaterial into cement system has succeeded to improve physical characteristics, mechanical properties, and novel performances of cementitious materials; however, the process is unable to reduce $\mathrm{CO}_{2}$ emission during the production of cement. From the review of the existing literature, it is apparent that the production of the cementitious material without emitting $\mathrm{CO}_{2}$ has not been studied yet. In a previous study [17], we have demonstrated the chemical synthesis of the alternative cementitious material; however, the structure property relation was not evaluated. In order to minimize the emission of $\mathrm{CO}_{2}$ and to produce alternative cementitious material, we have tried to establish an innovative alternative pathway. In this investigation, we have studied the chemical synthesis, structure property correlation, and application of the cementitious material. The chemical synthesis of nanocement is demonstrated to be very effective not only to enhance the physical and mechanical performances of cement based material but also to control the $\mathrm{CO}_{2}$ emission during its production.

\section{Experimental Program}

In this investigation, we have set a systematic experimental program to synthesize an alternative cementitious material (nanocement) using the hydrothermal method. For the synthesis of the nanocement using the hydrothermal method, 
initially, the raw materials were selected carefully, which did not emit $\mathrm{CO}_{2}$ in any step of the synthesis. Finally, the nanocement based mortar was fabricated and characterized.

2.1. Materials. The alternative cementitious material (nanocement) was synthesized using $99.9 \%$ pure nanosilica purchased from Asia Cement Manufacturing Co. Ltd., Daegu, Korea. The particle size, specific gravity, and surface area of the used nanosilica are reported to be $40 \mathrm{~nm}, 0.13$, and $65 \mathrm{~m}^{2} / \mathrm{g}$, respectively.

The other chemicals such as sodium aluminate, sodium hydroxide pellet purified (98\%), triethanol amine (TEA), and calcium nitrate used for the synthesis of the nanocement were purchased from Sigma Aldrich, Korea.

Nanocement mortar was fabricated using the fine aggregate of the average particle size $<0.6 \mathrm{~mm}$. The specific gravity, fineness modulus, and water absorption of the used fine aggregate are estimated to be $2.63,2.48$, and $0.1 \%$, respectively.

2.2. Synthesis of Nanocement. The synthesis of the alternative cementitious material (nanocement) using the hydrothermal process was performed subsequent to the preparation of the silica and alumina source materials. At the first step of the synthesis, $6.7 \mathrm{~g}$ of sodium hydroxide was dissolved in $100 \mathrm{~mL}$ of deionized water in a Pyrex flux. Afterwards, $3.8 \mathrm{~g}$ of sodium aluminate was added gently in the flux. The flux was then placed on a heating mantle for $10-15$ min maintaining the temperature of the mantle at $90^{\circ} \mathrm{C}$ to dissolve the material in the solution. After completion of this process, the flux was then allowed to cool and left to attain the ambient temperature. Thereafter, $16.4 \mathrm{~g}$ of triethanol amine was added dropwise as an emulsifier to prevent the precipitation of the prepared alumina source. Subsequently, the prepared alumina source was then allowed to ripen for $24 \mathrm{~h}$ to produce a soft gel material. Additionally, in the second step of the synthesis, exactly $12.5 \mathrm{~g}$ of the pure nanosilica was added to $100 \mathrm{~mL}$ of deionized water in an another pyrex flux. The flux was then placed on a magnetic stirrer to prepare a thick gel of silica source material. Thereafter, the thick gel of the silica source material was allowed to ripen for $24 \mathrm{~h}$ at ambient condition. Subsequently, the prepared source materials of the silica and alumina were mixed together using a turbine mixture, followed by $3 \mathrm{~h}$ sonication to disperse the components homogeneously. Consequently, the compound synthesized in this process was then allowed to dry in oven at $105^{\circ} \mathrm{C}$ for 15 days. The crystallized product, thus obtained, was then washed with distilled water and filtered off using a membrane filter. Finally, the residue was allowed to dry in oven at $105^{\circ} \mathrm{C}$ for $6 \mathrm{~h}$ followed by grinding in a mortar pestle to obtain a powder material.

Typically, the Portland cement contains three principal ingredients such as $\mathrm{SiO}_{2}, \mathrm{Al}_{2} \mathrm{O}_{3}$, and $\mathrm{CaO}$. The material synthesized in this investigation carried adequate amount of $\mathrm{SiO}_{2}$ and $\mathrm{Al}_{2} \mathrm{O}_{3}$; however, it did not contain $\mathrm{CaO}$. In this context, the powder material was treated with the calcium nitrate $\left(\mathrm{Ca}\left(\mathrm{NO}_{3}\right)_{2}\right)$ solution to increase the $\mathrm{CaO}$ content. Finally, the sample was allowed to centrifuge and filtered off, followed by oven drying at $105^{\circ} \mathrm{C}$ for $24 \mathrm{~h}$. The product thus obtained was then ground to acquire a powder of the alternative cementitious material (nanocement).

2.3. Fabrication of Nanocement Mortar. Cement mortar was fabricated using chemically synthesized nanocement, fine aggregate, alkali activator, and water. In this investigation, the $50 \%$ sodium hydroxide solution was used as an alkali activator for the fabrication of the nanocement based mortar. The samples were prepared varying the water content, alkali activator content, and fine aggregate content. In a particular batch mixing of the nanocement based mortar, $100 \mathrm{~g}$ of nanocement was mixed with fine aggregate (varying amounts $\sim 200 \mathrm{~g}-400 \mathrm{~g}$ ) followed by the mixing with an alkali activator (varying amounts $\sim 30 \mathrm{~mL}-95 \mathrm{~mL}$ ) and water (varying amounts $\sim 20 \mathrm{~mL}-50 \mathrm{~mL}$ ). Additionally, a control cement mortar was fabricated using $100 \mathrm{~g}$ of the Portland cement, $314 \mathrm{~g}$ of fine aggregate, and $50 \mathrm{~mL}$ of water. Table 2 represents the formulation code and the weight of different components for the fabrication of the control mortar as well as nanocement mortar. Finally, the prepared mortar samples were then cast immediately in the cubic mold of the dimension $50 \times 50 \times 50 \mathrm{~mm}^{3}$ and allowed to set for $24 \mathrm{~h}$. After complete setting, the cement mortar samples were then allowed to water cure for $3,7,14$, and 28 days. After completion of the desired curing time, the mortar samples were removed from the curing chamber and tested. The results were compared with the control sample. As represented in Table 2, the formulation code MN-W indicates that the nanocement mortar is fabricated using varying amounts of water content. Similarly the formulation code MN-A refers to the nanocement mortar fabricated using varying amounts of alkali activator content and the code MN-F implies that the nanocement mortar is fabricated using varying amounts of fine aggregate content. Additionally, the formulation code CCM refers to the control cement mortar.

\subsection{Characterization}

2.4.1. Physical Properties of Cement. The specific gravity and fineness of the chemically synthesized nanocement were analyzed in accordance with the Korean standard KS L 5110 [18]. Particle size distribution of the cementitious material synthesized in this investigation was performed using LA950 Laser particle size analyzer instrument, purchased from Horiba Ltd. Kyoto, Japan. For the analysis of the cement samples, initially, the samples were dried in oven at $105^{\circ} \mathrm{C}$ to remove the moisture. During the particle size analysis, exactly $1 \mathrm{~g}$ of the dry samples was fed into the PowderJet Dry Feeder of the LA-950 Laser particle size analyzer. Furthermore, samples were analyzed based on the Mie scattering theory. In this instrument, two light sources are used to analyze the particle size, namely, $5 \mathrm{~mW}, 650 \mathrm{~nm}$ red laser diode, and $3 \mathrm{~mW}, 405 \mathrm{~nm}$ blue LED. In the measurement array, the high quality photodiodes are used to detect the scattered light over a wide range of angles. The results obtained from these experiments were compared with the ordinary Portland cement and Portland pozzolana cement. 
TABLE 2: Formulation code and mix proportions of components for the fabrication of control as well as nanocement mortar.

\begin{tabular}{|c|c|c|c|c|c|}
\hline \multirow{2}{*}{ Type of variability } & \multirow{2}{*}{ Formulation code } & \multicolumn{4}{|c|}{ Components } \\
\hline & & Cement (g) & Water $(\mathrm{mL})$ & $50 \% \mathrm{NaOH}$ solution $(\mathrm{mL})$ & Fine aggregate $(\mathrm{g})$ \\
\hline Control & CCM & $100^{\mathrm{a}}$ & 50 & - & 314 \\
\hline \multirow{7}{*}{ Water variation } & MN-W1 & $100^{\mathrm{b}}$ & 12 & 50 & 314 \\
\hline & MN-W2 & $100^{\mathrm{b}}$ & 16 & 50 & 314 \\
\hline & MN-W3 & $100^{\mathrm{b}}$ & 20 & 50 & 314 \\
\hline & MN-W4 & $100^{\mathrm{b}}$ & 24 & 50 & 314 \\
\hline & MN-W5 & $100^{\mathrm{b}}$ & 29 & 50 & 314 \\
\hline & MN-W6 & $100^{\mathrm{b}}$ & 40 & 50 & 314 \\
\hline & MN-W7 & $100^{\mathrm{b}}$ & 50 & 50 & 314 \\
\hline \multirow{8}{*}{ Alkali activator variation } & MN-A1 & $100^{\mathrm{b}}$ & 20 & 30 & 314 \\
\hline & MN-A2 & $100^{\mathrm{b}}$ & 20 & 40 & 314 \\
\hline & MN-A3 & $100^{\mathrm{b}}$ & 20 & 50 & 314 \\
\hline & MN-A4 & $100^{\mathrm{b}}$ & 20 & 60 & 314 \\
\hline & MN-A5 & $100^{\mathrm{b}}$ & 20 & 70 & 314 \\
\hline & MN-A6 & $100^{\mathrm{b}}$ & 20 & 80 & 314 \\
\hline & MN-A7 & $100^{\mathrm{b}}$ & 20 & 90 & 314 \\
\hline & MN-A8 & $100^{\mathrm{b}}$ & 20 & 95 & 314 \\
\hline \multirow{4}{*}{ Course aggregate variation } & MN-F1 & $100^{\mathrm{b}}$ & 20 & 50 & 200 \\
\hline & MN-F2 & $100^{\mathrm{b}}$ & 20 & 50 & 245 \\
\hline & MN-F3 & $100^{\mathrm{b}}$ & 20 & 50 & 300 \\
\hline & MN-F4 & $100^{\mathrm{b}}$ & 20 & 50 & 400 \\
\hline
\end{tabular}

${ }^{\mathrm{a}}$ Ordinary Portland cement. ${ }^{\mathrm{b}}$ Chemically synthesized nanocement.

2.4.2. Chemical Composition Analysis. Chemical compositions of the cementitious material synthesized in this investigation were analyzed using Rigaku NEX QC energy dispersive X-ray fluorescence (EDXRF) analyzer, Applied Rigaku Technologies, Inc., Austin, USA. Before the analysis, cement samples were dried in oven at $105^{\circ} \mathrm{C}$ and cooled to room temperature by storing the samples in a vacuum desiccator. The cement samples were analyzed packing the samples on a $40 \mathrm{~mm}$ rectangular hollow area of the sample holder. Thereafter, the analysis was performed in helium environment. In this instrument, a $50 \mathrm{Kv} \mathrm{X}$-ray generator tube is used to generate the X-ray for the analysis of the sample and a high performance SDD semiconductor based recorder is used to detect the signal. The result obtained from this experiment was further clarified by the energy dispersive Xray spectroscopy (EDX).

2.4.3. FE-SEM Analysis. Field emission scanning electron microscopic (FE-SEM) images of the synthesized nanocement and commercially available Portland cement were recorded using JEOL JSM-6700F, JEOL USA Inc., USA. In this microscope, the electrons are emitted from a bent tungsten filament (withstand high temperature without melting). The emitted electrons are accelerated by the application of high voltage (maximum $30 \mathrm{kV}$ ) which in turn leads to strike on the surface of the sample; consequently, the electrons are liberated from the outer shell of the sample. The liberated electrons are termed as secondary electron, focused by electromagnetic lenses with a maximum magnification capacity 1000000x. The scanning of the electron beam over the sample surface is controlled by deflecting the electron beam using a scanning coil. During this investigation, a very thin gold was sputter coated on the surface of the moisture free dried samples to avoid charging. Thereafter, samples were placed on the SEM stub and allowed to analyze. The digital scanning electron micrographs were recorded in $10-20 \mathrm{kV}$ accelerated voltage and $15 \mathrm{kx}$ magnification.

2.4.4. Setting Time Measurement. Setting times (initial and final) of the newly synthesized cementitious material (nanocement) as well as Portland cement were estimated in accordance with the standard KS L 5108 [19]. This is a standard method to predict the setting time of the hydraulic cement using Vicat apparatus.

2.4.5. X-Ray Diffraction Analysis. The structural characteristics of the chemically synthesized cementitious material were examined using an X-ray diffractometer (Ultima III, Rigaku Inc., Japan). The $\mathrm{CuK} \alpha$ radiation $(40 \mathrm{kV}, 40 \mathrm{~mA})$ and $\mathrm{Ni}$ filter were used to produce the $\mathrm{X}$-ray. The $\mathrm{X}$-ray diffractograms of the samples were recorded in the $2 \theta$ range $5^{\circ}-60^{\circ}$, maintaining a scan speed of $1^{\circ} \mathrm{min}^{-1}$ with a step difference of $0.02^{\prime \prime}$. In this investigation, X-ray diffraction of the oven-dried samples was recorded by packing the samples in a rectangular hollow area of the glass made sample holder. In this instrument, a tungsten (W) filament is used as cathode and a desired target metal; for example, $\mathrm{Cu}$ is used as an anode 
TABLE 3: Physical properties of the synthesized nanocement as well as commercially available different types of cement.

\begin{tabular}{lcccc}
\hline \multirow{2}{*}{ Properties } & & \multicolumn{2}{c}{ Type of cement } & \\
& Ordinary Portland cement & Blast furnace slag cement & Fly ash based cement & Synthesized nanocement \\
\hline Particle size $(\mu \mathrm{m})$ & $10 \sim 30$ & $10 \sim 30$ & $20 \sim 30$ & 0.167 \\
Specific gravity & 3.15 & 3.03 & 2.94 & 2.11 \\
Fineness $\left(\mathrm{cm}^{2} / \mathrm{g}\right)$ & $\sim 2800$ & $\sim 2600$ & $\sim 2500$ & 3582400 \\
\hline
\end{tabular}

TABLE 4: Oxide composition (\%) present in nanocement as well as ordinary Portland cement.

\begin{tabular}{lcccccccc}
\hline \multirow{2}{*}{ Type of cement } & \multicolumn{3}{c}{ Chemical composition (\%) } \\
& $\mathrm{CaO}$ & $\mathrm{Na}_{2} \mathrm{O}$ & $\mathrm{SiO}_{2}$ & $\mathrm{Al}_{2} \mathrm{O}_{3}$ & $\mathrm{MgO}$ & $\mathrm{Fe}_{2} \mathrm{O}_{3}$ & $\mathrm{SO}_{3}$ & $\mathrm{Loss}_{\text {of Ig }}$ \\
\hline Ordinary Portland cement & 64.33 & - & 20.36 & 5.77 & 2.05 & 2.84 & 2.51 & 2.0 \\
Chemically synthesized nanocement & 3.71 & 5.31 & 42.8 & 21.9 & 0.41 & 2.37 & - & 0.32 \\
\hline
\end{tabular}

to produce the monochromatic X-ray beam of the wavelength $1.5 \AA$.

2.4.6. Compressive Strength Measurement. The compressive strength of the nanocement based mortar as well as control cement mortar of the dimension $50 \times 50 \times 50 \mathrm{~mm}^{3}$ was measured using a universal testing machine with a loading rate $0.06 \mathrm{MPa} / \mathrm{min}$ in accordance with the Korean standard KS F 2405 [20].

\section{Results and Discussion}

3.1. Physical Properties. Table 3 represents the physical properties such as particle size, specific gravity, and fineness of the chemically synthesized alternative cementitious material (nanocement). The results are compared with the commercially available Portland cement and Portland pozzolana cement. As observed from the table, particle size of the chemically synthesized cement is $\sim 0.168 \mu \mathrm{m}(168 \mathrm{~nm})$, which is significantly smaller as compared to that of the ordinary Portland and Portland pozzolana cement. The particle size distribution pattern of the newly synthesized cement is represented in Figure 1. From the figure, it is observed that the particle size of the cement synthesized in this investigation belongs to nanometer scale. Therefore, it is considered that the process used in this investigation is able to synthesize an alternative cementitious material of the nanoscale particle size. From Table 3, it is also visualized that the fineness of the synthesized cementitious material is quite higher as compared to that of the commercially available ordinary Portland and Portland pozzolana cement. It is reported elsewhere that the smaller particle size leads to increase in the fineness of the cement [21]. As evidenced from Table 3, it can be considered that the higher fineness of the cement leads to increase in the surface area, which in turn increases the volume of the cement, and consequently minimizes the specific gravity.

3.2. Chemical Analysis. Subsequent to the analysis of the physical performances, the chemical compositions were also analyzed to assess the basic chemical characteristics

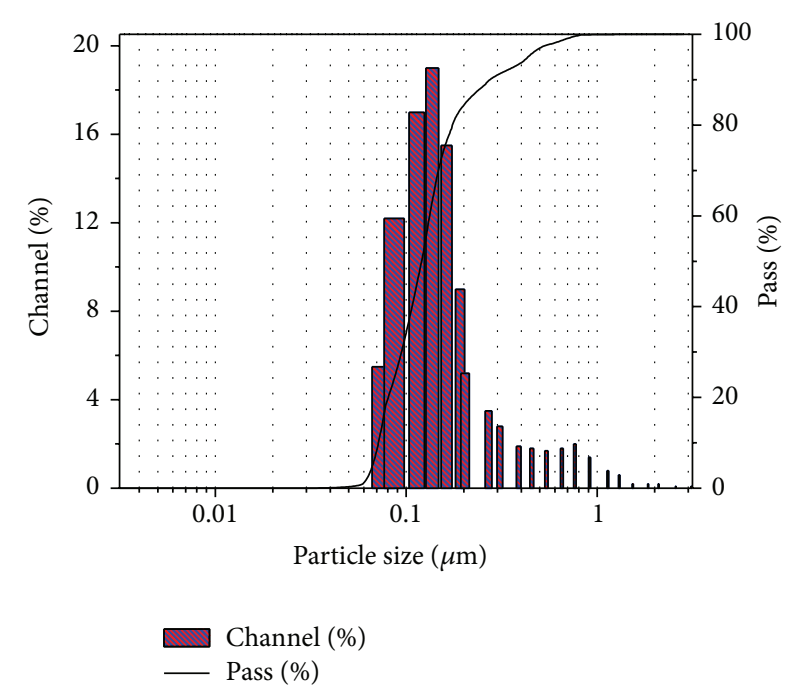

FIGURE 1: Particle size distribution pattern of the chemically synthesized nanocement.

of the synthesized cementitious material. Typically, cement contains dicalcium silicate $\left(\mathrm{C}_{2} \mathrm{~S}\right)$, tricalcium silicate $\left(\mathrm{C}_{3} \mathrm{~S}\right)$, tricalcium aluminate $\left(\mathrm{C}_{3} \mathrm{~A}\right)$, and tetracalcium aluminoferrite $\left(\mathrm{C}_{4} \mathrm{AF}\right)$ phases $[22,23]$. The mentioned phases are predominantly composed of oxide components of the calcium, silicon, aluminium, and iron. Table 4 represents the oxide compositions of the ordinary Portland cement as well as chemically synthesized nanocement. From the table, it is envisaged that the chemically synthesized nanocement as well as ordinary Portland cement contains identical oxide phases; however, the quantities of the chemical constituents of these two cements are not identical. This is due to the difference in source material used for the synthesis of the nanocement and the production of ordinary Portland cement. Additionally, it is visualized from Table 4 that higher amounts of silica, alumina, and sodium oxide are carried by the chemically synthesized cementitious material as compared to that of the ordinary Portland cement. This phenomenon can further be supported by EDX analysis. Accordingly, it is reported elsewhere that the hydration of the Portland cement usually 


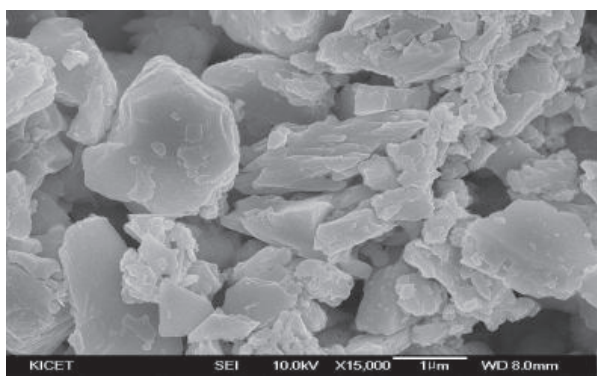

(a)

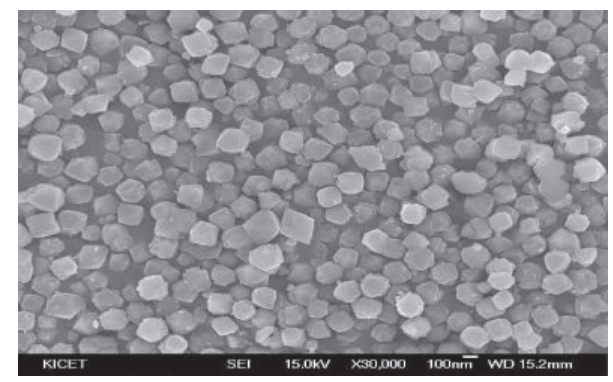

(b)

FIGURE 2: FE-SEM micrographs of the (a) ordinary Portland cement and (b) chemically synthesized nanocement.

TABLE 5: Identification of the chemical constituents of the nanocement by EDX.

\begin{tabular}{lccccc}
\hline \multirow{2}{*}{ Type of the cement } & \multicolumn{5}{c}{ Chemical constituents (\%) } \\
& $\mathrm{Ca}$ & $\mathrm{Na}$ & $\mathrm{Al}$ & $\mathrm{Si}$ & $\mathrm{O}$ \\
\hline Nanocement & 10.09 & 2.00 & 25.05 & 32.62 & 30.24 \\
\hline
\end{tabular}

produces calcium silicate hydrate and calcium hydroxide predominantly [22], whilst hydration of the chemically synthesized cementitious material may produce calcium sodium alumino silicate hydrate in addition with calcium silicate hydrate and calcium hydroxide. Therefore, from the chemical composition analysis, it is acquainted that the method used in this investigation is the unique scheme to synthesize an alternative cementitious material of nanoscale particle size (nanocement) without clinkering at high temperature.

3.3. FE-SEM and EDX Analysis. Figures 2(a) and 2(b) represent the field emission scanning electron micrographs of the Portland cement and the chemically synthesized cement, respectively. From Figure 2(a), it is clearly visualized that the particle size of the ordinary Portland cement is belonging in microscale level, whilst the particle size of the chemically synthesized cement is belonging to the nanoscale level (Figure 2(b)). From the figures, it is also perceived that the ordinary Portland cement particles have structural inequality, whereas the particles of the chemically synthesized cementitious material have quite structural similarity. Therefore, from the FE-SEM analysis of the cement particles, it is appraised that the process used in this investigation is able to synthesize nanoscale cement particle. During the FE-SEM analysis, EDX was also performed to clarify the chemical constituents present in the synthesized cementitious material (nanocement). Figure 3 represents the EDX analysis of the chemically synthesized cementitious material (nanocement). Table 5 represents the summary of Figure 3. From the table, it is visualized that the chemically synthesized cementitious material as well as ordinary Portland cement contains identical chemical constituents.

3.4. Setting Time. Setting time of the cement is one of the important characteristics and provides the information of

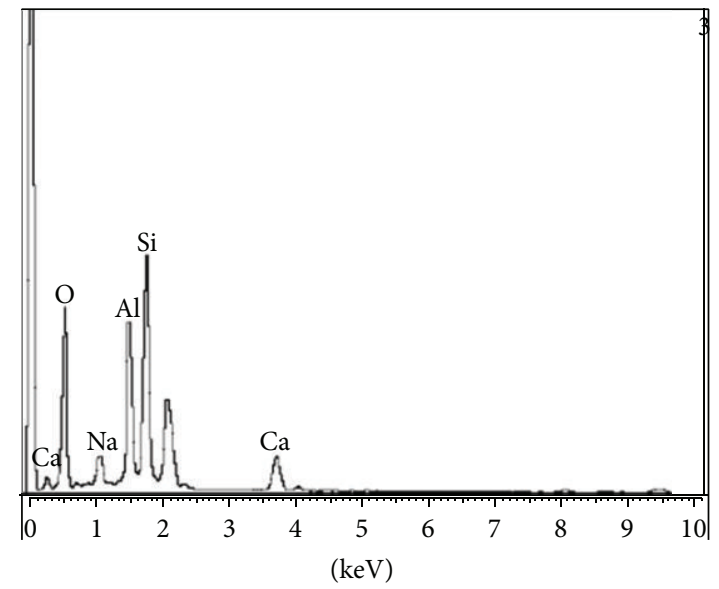

FIGURE 3: EDX analysis of chemically synthesized nanocement.

how long concrete maintains its liquidity. It is an output of the hydration reaction occurring among the chemical phases of the cement in the presence of water as reacting medium. In this investigation, setting of the chemically synthesized nanocement is occurring due to the condensation reaction of the reacting phases in the presence of an alkali activator (50\% $\mathrm{NaOH}$ solution). In the present investigation, the cementitious material was synthesized from the pozzolanic material (nanosilica) infused with hydrated alumina using the hydrothermal method. Therefore, the occurrence of the hydration reaction among the chemical phases is difficult in the presence of the water only. Hence, the use of an alkali activator in aqueous solution may achieve driving force to allow the hydration reaction and leads to setting of the cementitious material. Figure 4 represents the variation of setting times (initial and final) of the chemically synthesized nanocement with increase in curing temperature. From the figure, it is visualized that the initial and final setting times of the nanocement decrease significantly with increase in curing temperature. As envisaged from Figure 4, the initial and final setting times of the nanocement were $230 \mathrm{~min}$ and $540 \mathrm{~min}$, respectively, at $30^{\circ} \mathrm{C}$, which are considerably reduced to $22 \mathrm{~min}$ and $27 \mathrm{~min}$, respectively, at the curing temperature $60^{\circ} \mathrm{C}$. Beyond this temperature, the decrement 


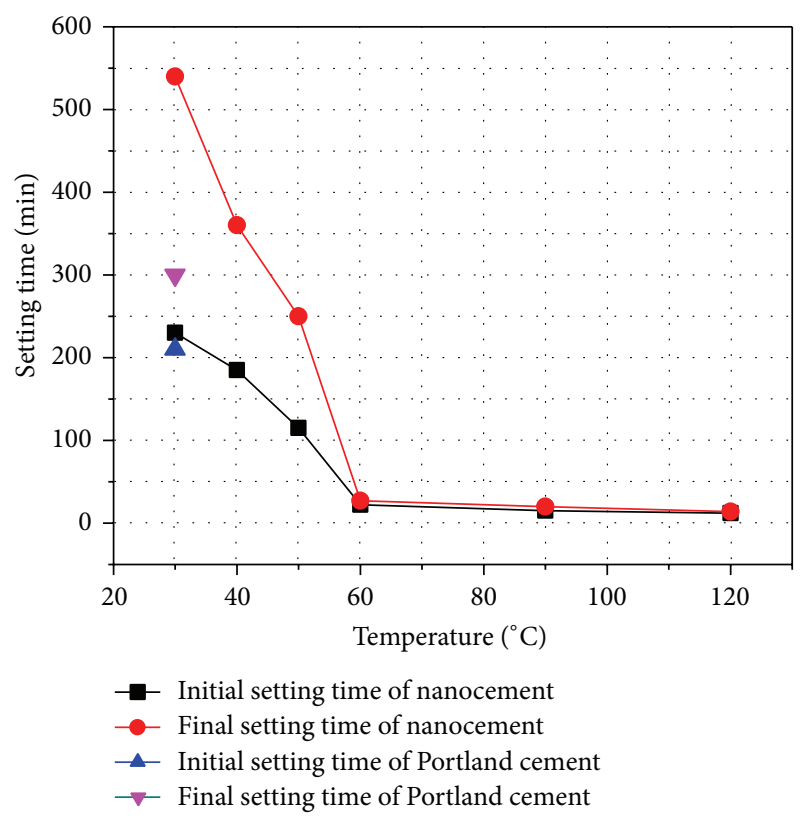

Figure 4: Initial and final setting times of the ordinary Portland cement at $30^{\circ} \mathrm{C}$ and the variation of the initial and final setting times of the chemically synthesized nanocement with increase in curing temperature.

of the setting times slows down and becomes almost constant at $90^{\circ} \mathrm{C}$. Hence, it is considered that the alkali activated condensation reaction proceeds very fast at the temperature range $60^{\circ} \mathrm{C}-90^{\circ} \mathrm{C}$ as compared to that of the normal temperature $\left(30^{\circ} \mathrm{C}\right)$. From Figure 4, the initial and final setting times of the ordinary Portland cement are estimated to be 210 and $300 \mathrm{~min}$, respectively, at $30^{\circ} \mathrm{C}$. It is reported in Korean standard KS L 5201 [24] that a standard cement should have the initial setting time more than $60 \mathrm{~min}$ and final setting time less than $10 \mathrm{~h}$ at ambient condition. Accordingly, in this investigation, the ordinary Portland cement as well as the chemically synthesized nanocement tracks the Korean standard. Therefore, from the setting time analysis, it is considered that the cementitious material synthesized using the hydrothermal method can be used for the normal construction as well as rapid construction purpose.

3.5. Compressive Strength. Subsequent to the analysis of the physical, chemical, and fresh properties of the synthesized material, the mechanical performance of the chemically synthesized nanocement has been elucidated measuring the compressive strength of the nanocement based mortar. In this investigation, different mortar samples were fabricated varying the water content, alkali activator content, and fine aggregate content. In this investigation, the compressive strength of the nanocement mortar is compared with the control cement mortar fabricated using ordinary Portland cement. Comparing the compressive strength of the nanocement mortar with the ordinary Portland cement, it is assessed that the nanocement based mortar performs similarly or better as compared to that of the ordinary Portland cement.

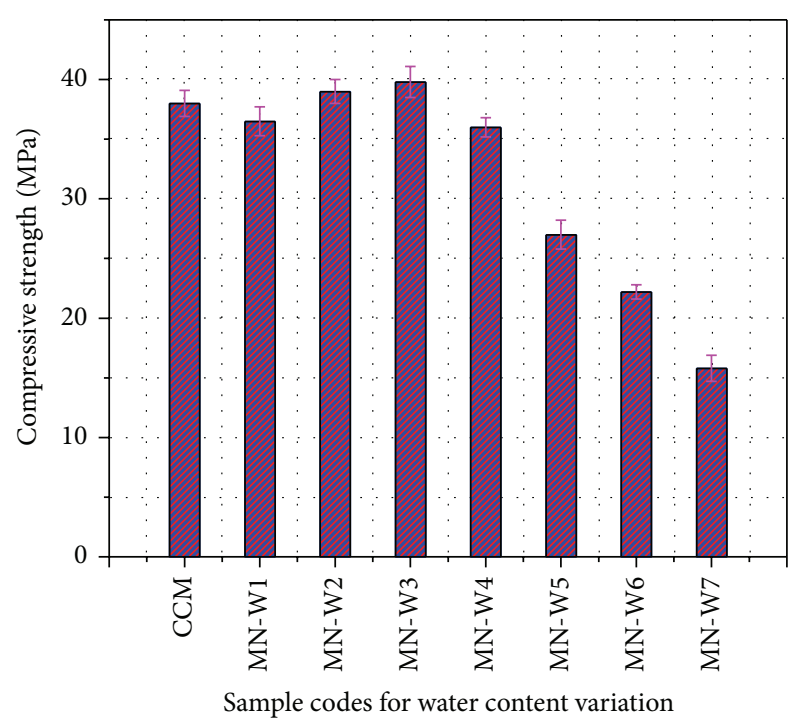

FIGURE 5: Compressive strength of control mortar and variation of the compressive strength of nanocement based mortar with increase in water content.

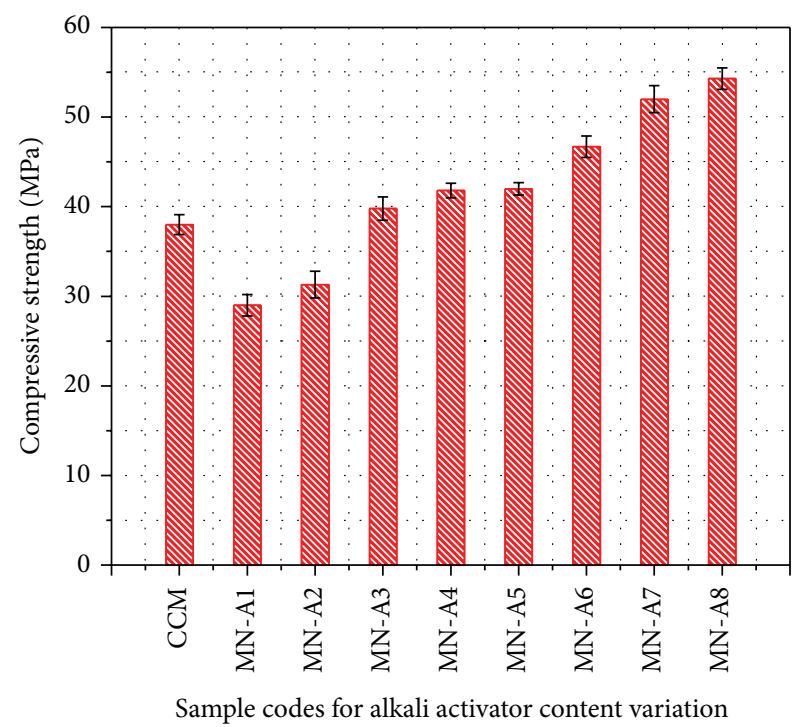

FIGURE 6: Compressive strength of control mortar and variation of the compressive strength of nanocement based mortar with increase in alkali activator content.

Figure 5 represents the variation of compressive strength of nanocement mortar (cured for 7 days) with increase in water content (weight $\%$ with respect to weight of nanocement). As visualized from the figure, compressive strength of the mortar increases initially up to $20 \%$ water content followed by reducing with further increases in water content. It indicates that maximum compressive strength of the nanocement based mortar is achieved at $20 \%$ water content. Hence, it is considered that the lower water content shows better performance in compressive strength of the nanocement based mortar. Similarly, Figures 6 and 7 represent the variation of the compressive strength with increase in alkali activator content 


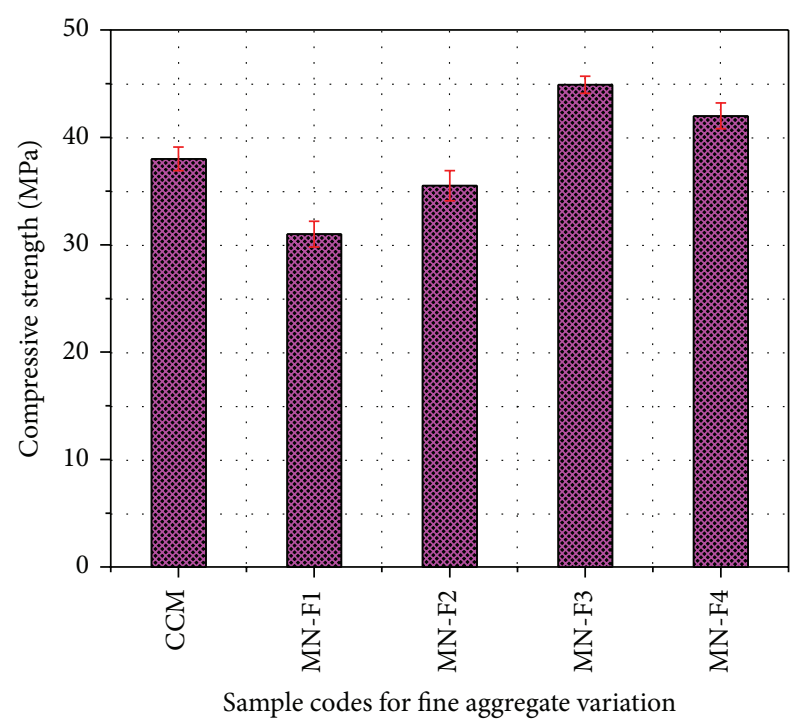

FIGURE 7: Compressive strength of control mortar and variation of the compressive strength of nanocement based mortar with increase in fine aggregate content.

and fine aggregate content, respectively. From Figure 6, it is revealed that the compressive strength of the nanocement mortar increases gradually with increase in alkali activator content. This is may be due to the occurrence of the faster rate condensation reaction among the chemical phases of nanocement in the presence of a higher alkali activator and lower water content. From Figure 7, it is observed that the compressive strength of the nanocement mortar increases gradually with increase in fine aggregate content up to $300 \mathrm{wt}$. $\%$, followed by decreasing with further increase in aggregate content. Therefore, analyzing the compressive strength, it is appraised that the mortar fabricated using nanocement shows superior mechanical performance in the presence of higher alkali activator content, lower water content, and optimized fine aggregate content ( $\sim 300$ weight \%).

As it seems from the setting time analysis the setting of the nanocement occurs very fast at high temperature $\left(\sim 90^{\circ} \mathrm{C}\right)$. Keeping the effect in mind, a nanocement based mortar was prepared using $100 \mathrm{~g}$ cement, $95 \mathrm{~g}$ of alkali activator $(50 \%$ $\mathrm{NaOH}$ solution), and $314 \mathrm{~g}$ of fine aggregate and allowed to cure in two different temperatures to evaluate the effect of high temperature on the mechanical performance of the mortar. Analyzing the result, the compressive strengths after 3 days and 7 days curing of the mortar fabricated using the above-mentioned mix design and cured at $90^{\circ} \mathrm{C}$ are estimated to be $\sim 62.6 \mathrm{MPa}$ and $65 \mathrm{MPa}$, respectively, whilst the compressive strengths after 3 days and 7 days curing of the mortar fabricated using the same mix design and cured at normal temperature $\left(30^{\circ} \mathrm{C}\right)$ are estimated to be $\sim 56 \mathrm{MPa}$ and $61.5 \mathrm{MPa}$, respectively. The rapid development of the compressive strength at high temperature confirms the fast occurrence of condensation reaction of the chemical phases present in nanocement.

In addition to the effect of curing temperature, the effect of curing time on the compressive strength of nanocement

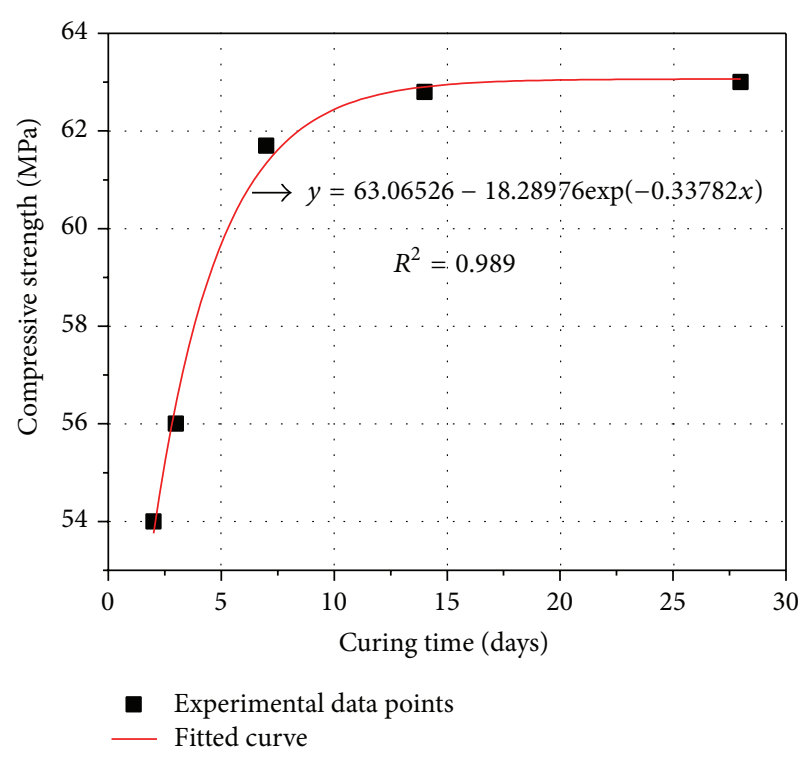

FIGURE 8: Variation of the compressive strength of the nanocement based mortar as the function of curing time.

based mortar has also been investigated. Figure 8 represents the variation of the compressive strength of the nanocement based mortar (fabricated at normal temperature) as a function of the curing time. From the figure, it is envisaged that the compressive strength of the nanocement mortar increases gradually with increase in curing time up to 14 days. Beyond two weeks of curing, compressive strength becomes almost constant. It indicates that 14-day curing is sufficient for nanocement mortar to gain maximum strength, whereas, for ordinary Portland cement based mortar, 28-day curing is essential to gain adequate strength. Therefore, it is assessed that the chemically synthesized nanocement has the ability to produce adequate strength of the mortar within 14-day curing, which in turn reduces the time required for construction.

Viewing in light of the above results, it is revealed that the method used in this investigation is an innovative scheme to produce an alternative cementitious material of the nanoscale particle size. In fact, in this investigation, an alternative pathway is followed instead of the clinkering to produce a cementitious material using pozzolanic material (nanosilica) infused with hydrated alumina. Based on the results reported above, we are trying to explain plausible chemical reactions involved in the synthesis of nanocement and its overall performances as well. Figure 9 represents a plausible model associated with synthesis of nanocement. Initially, the starting material sodium aluminate $\left(\mathrm{NaAlO}_{2}\right)$ was dissolved in alkaline water at $90^{\circ} \mathrm{C}$ to form a glassy chain of sodiated aluminium hydroxide, and at the same time nanosilica was dissolved in water to form a high density hydrated gel. Afterwards, mixing of the sodiated aluminium hydroxide glassy gel with the high density gel of hydrated silica leads to forming sodium aluminum silicate compounds $[5,25]$. Heat evaporation process influences the nucleation 


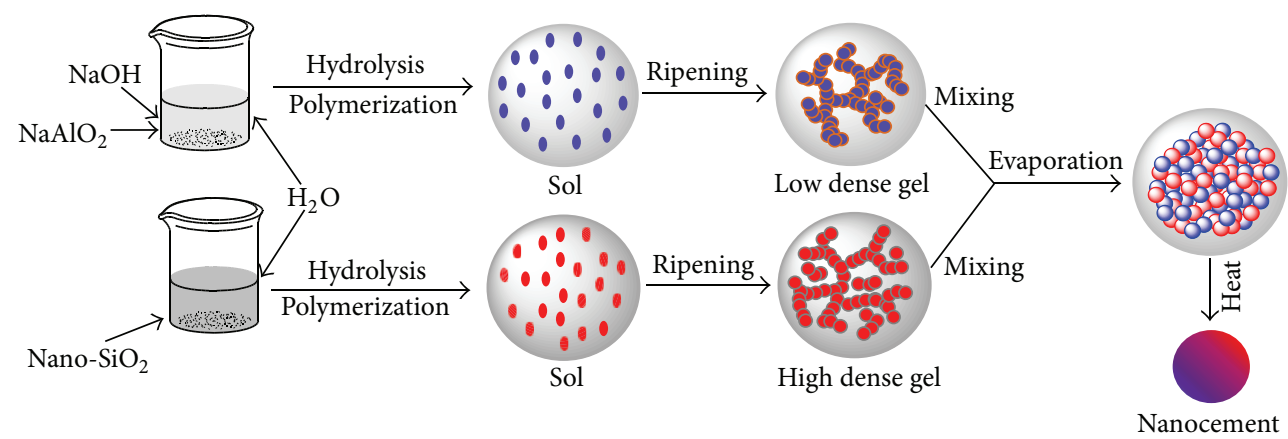

FIGURE 9: Plausible model for chemical synthesis of the nanocement using bottom-up nanotechnology.

$\mathrm{NaAlO}_{2}+\mathrm{NaOH}+\mathrm{H}_{2} \mathrm{O} \longrightarrow \mathrm{NaAl}(\mathrm{OH})_{4}$
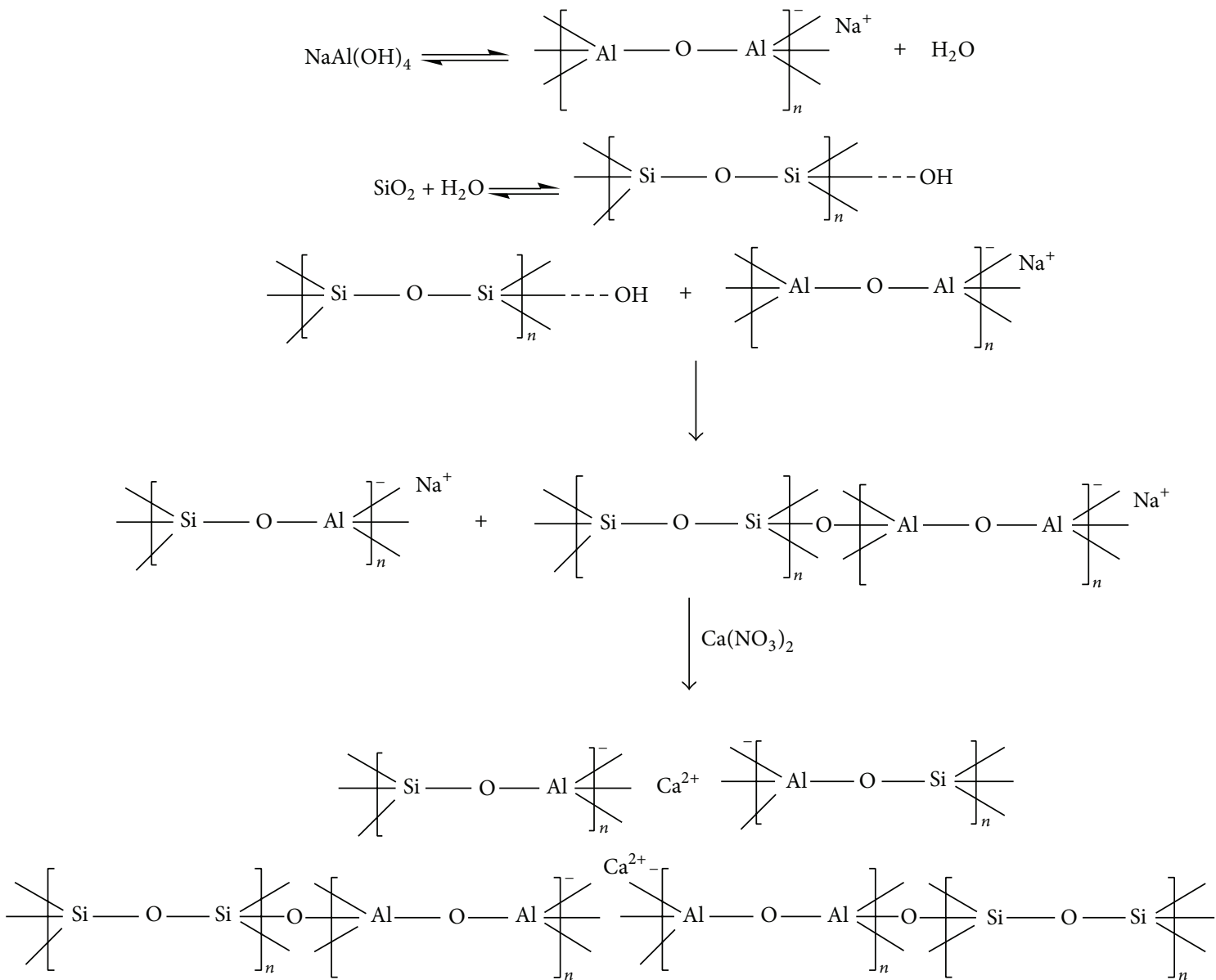

FIGURE 10: Plausible reaction scheme for the synthesis of nano cement.

and crystallization of the sodium aluminum silicate compounds. The plausible reaction schemes are represented in Figure 10. Furthermore, to increase the calcium ion content in synthesized cementing material, ion substitution was done in the presence of calcium nitrate $\mathrm{Ca}\left(\mathrm{NO}_{3}\right)_{2}$ shown in (5) of the Figure 10. The synthesized material was then used for the fabrication of nanocement based mortar. In the present investigation, the cementitious material was synthesized from the pozzolanic material (nanosilica) infused with hydrated alumina using the hydrothermal method. Additionally, the occurrence of the hydration reaction among the chemical phases of the synthesized material is difficult in the presence of the water only. This is may be due to the lack of the driving force to initiate the hydration reaction in the presence of water. Hence, the use of an alkali activator in aqueous solution may achieve the driving force to allow the hydration 


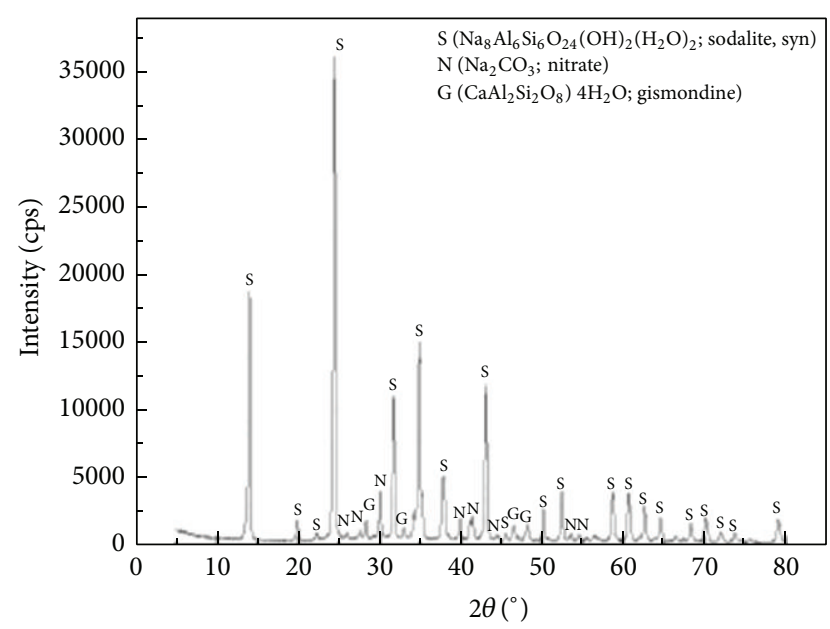

FIGURE 11: X-ray diffraction pattern of the chemically synthesized nanocement.

reaction and leads to hardening of the cementitious material. Therefore, for hydration, an activated sodium hydroxide solution was used. Accordingly, the alkaline hydration reaction of the alternative cementitious material possibly produces sodium and/or calcium alumino silicate based compounds such as sodalite, natrite, gismondine, calcium silicate hydrate gel, sodium alumino silicate hydrate gel, and calcium sodium alumino silicate hydrate gel $[5,26]$. The crystalline compounds such as sodalite $\left(\mathrm{Na}_{8} \mathrm{Al}_{6} \mathrm{Si}_{6} \mathrm{O}_{24}(\mathrm{OH})_{2}, 2 \mathrm{H}_{2} \mathrm{O}\right)$, natrite $\left(\mathrm{Na}_{2} \mathrm{CO}_{3}\right)$, and gismondine $\left(\mathrm{CaAl}_{2} \mathrm{Si}_{2} \mathrm{O}_{8}, 4 \mathrm{H}_{2} \mathrm{O}\right)$ formed by alkaline hydration of nanocement are identified in $\mathrm{X}$ ray diffractogram of hydrated nanocement represented in Figure 11. However, the gel compounds are not identified in the X-ray diffraction pattern due to their poor crystalline nature. Therefore, to analyze hydrated compounds and to establish their structures, MAS-NMR in conjugation with FTIR, TG, and DSC are required to be performed in the future. As it seems from the above the alkaline hydration of the chemically synthesized cement produces various gel and crystalline compounds, which may lead to develop the microstructure at the nano- and microscale level of the hydrated nanocement. Therefore, it can be anticipated that the performance of the nanocement may be controlled by the dispersion of the crystalline component over the gel compounds, which in turn leads to filling of the capillary pores at the nano- and microscale level. Accordingly, it is apparent that the reduction of the capillary pores increases the efficiency of the interfacial transition zone of hydrated cement, which in turn leads to increase in the strength of the mortar samples. In Figure 12 a plausible model has been represented in favor of the development of hydrated product into chemically synthesized nanocement system. As it is confirmed from Table 3 that the particle size of the synthesized cement belongs in nanometer level, therefore, it is expected that the higher surface area would be exposed for the hydration reaction [27], which in turn leads to developing of strength in mortar or concrete rapidly and, consequently, minimizes the time of construction.
Viewing in light of the hydrothermal synthesis of the cementitious material (nanocement), it is apparent that the raw materials used in this investigation are not carbon based. Accordingly, the process steps followed to produce nanocement are not responsible to emit $\mathrm{CO}_{2}$. Therefore, it is confirmed that the $\mathrm{CO}_{2}$ will not emit during the synthesis of the nanocement using the hydrothermal method. However, it is reported elsewhere that during the production of the 1 ton of Portland cement, $700-800 \mathrm{~kg} \mathrm{CO}_{2}$ is liberated [2]. Usually, the limestone is used as a primary raw material for the production of the Portland cement, which is mainly composed of $\mathrm{CaCO}_{3}$ (calcium carbonate). When the raw materials are heated up to $1450^{\circ} \mathrm{C}$ in the rotary kiln, it emits enormous $\mathrm{CO}_{2}$ [28]. Additionally, it is also reported that the $\mathrm{CO}_{2}$ is emitted during the calcination of the calcareous raw materials to produce $\mathrm{CaO}$ [29]. Accordingly, reviewing the worldwide report, it is considered that around $7 \%$ of the total man-made $\mathrm{CO}_{2}$ is emitted during the cement production [29]. Therefore, it is expected that the synthesis of the nanocement using hydrothermal procedure is an initial alternative approach, which will avoid the $\mathrm{CO}_{2}$ emission.

\section{Conclusion}

The present investigation offers an innovative idea to synthesize nanocement utilizing the hydrothermal method instead of the high temperature clinkering method which emits enormous carbon dioxide during the production of cement. In this investigation, the hydrothermal synthesis of the nanocement from nanosilica and sodium aluminate is considered as a bottom-up nanotechnology. Based on the physical properties analyses, the particle size, specific gravity, and fineness of the synthesized material are estimated to be $167 \mathrm{~nm}, 2.11$, and $3582400 \mathrm{~cm}^{2} / \mathrm{g}$, respectively. Hence, from the result, it is assessed that the product obtained by the chemical synthesis method is a nanomaterial. Additionally, FE-SEM analysis proves that the average particle size of the synthesized material is retained at nanoscale level. Additionally, based on the chemical composition analysis in conjugation with EDX analysis, it is revealed that the synthesized material contains identical chemical oxide phases with commercially available cement. Therefore, it is considered that the synthesized material is a type of cementitious material. Furthermore, based on the setting time measurement, it is concluded that the synthesized nanocement follows Korean standard in its setting behavior. Finally, viewing in light of the mechanical property analysis, it is assessed that the newly developed material shows cementing ability with superior mechanical performance as compared to that of the commercially available cement. Based on the critical analysis of the results, a plausible model as well as a reaction scheme has been established in favor of the synthesis and hydration of nanocement. Finally, it is concluded that the chemically synthesized cementitious material (nanocement) not only improves the physical and mechanical performance of the mortar and concrete but also brings several encouraging impacts to the society, including reduction of the $\mathrm{CO}_{2}$ emission. 

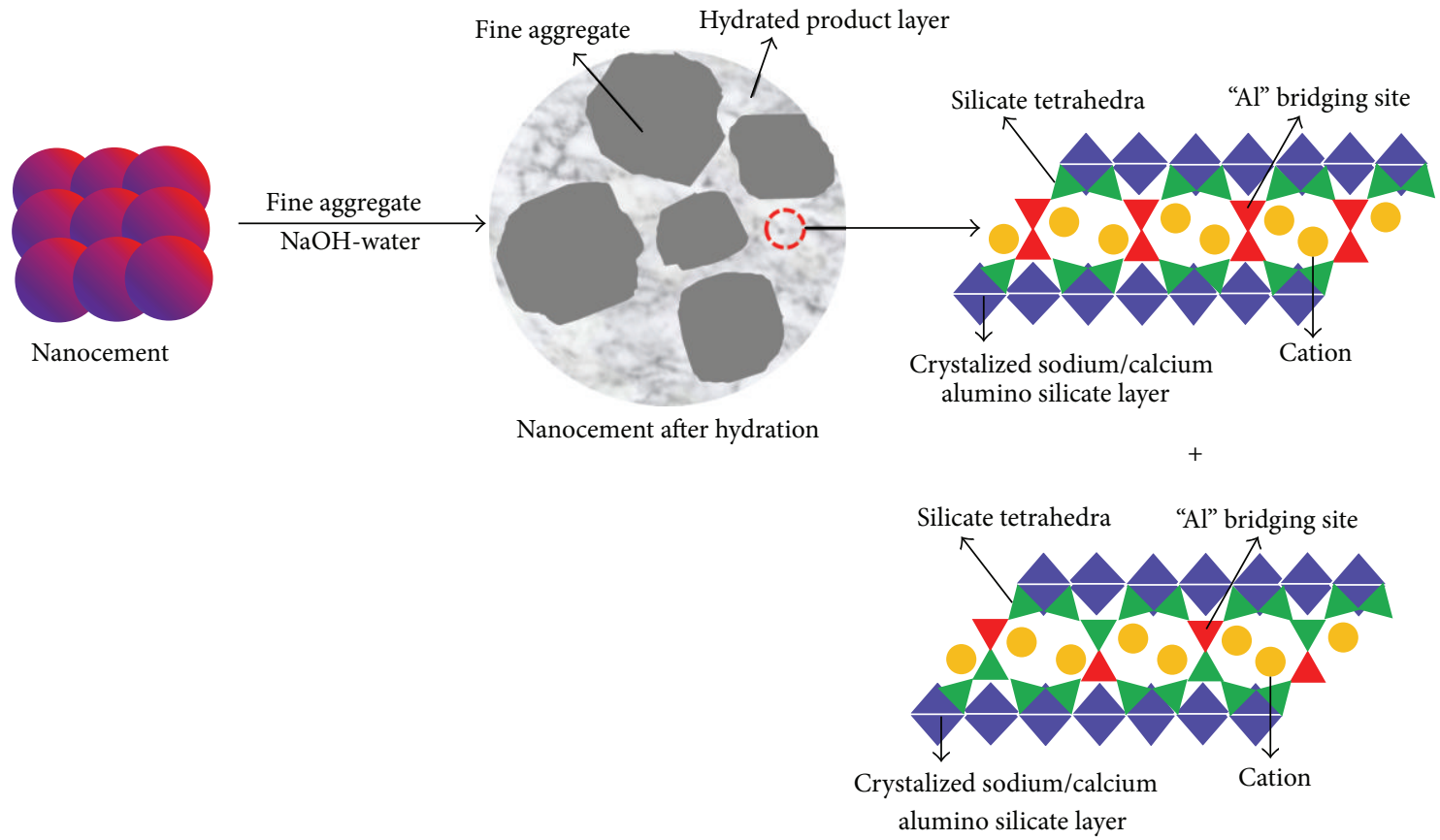

FIGURE 12: Plausible model based on hydration of nanocement and probable structure of the expected hydrated product, that is, sodiumcalcium-aluminosilicate hydrate.

\section{Conflict of Interests}

The authors declare that there is no conflict of interests regarding the publication of this paper.

\section{Acknowledgment}

The authors would like to acknowledge BK21, Republic of Korea, for their financial support to pursue this research program.

\section{References}

[1] J. Jacobsen, M. S. Rodrigues, M. T. F. Telling et al., "Nano-scale hydrogen-bond network improves the durability of greener cements," Scientific reports, Nature, vol. 3, article 2667, 2013.

[2] V. M. Malhotra, "Role of fly ash in reducing greenhouse gas emissions during the manufacturing of portland cement clinker," http://www.watancon.com/documentation/technical/ Malhotra_-_Role_of_Fly_Ash_in_reducing_GGE.pdf.

[3] P. Balaguru and K. Chong, "Nanotechnology and concrete: research opportunities," in Proceedings of the ACI Session on Nanotechnology of Concrete: Recent Developments and Future Perspectives, Denver, Colo, USA, November 2006, https://pantherfile.uwm.edu/sobolev/www/ACI/2-Balaguru-ACI-F.pdf.

[4] A. K. Mukhopadhyay, "Next-generation nano-based concrete construction products: a review," in Nanotechnology in Civil Infrastructure: A Paradigm Shift, K. Gopalakrishnan, B. Birgisson, P. Taylor, and N. O. Attoh-Okine, Eds., pp. 207223, Springer, Berlin, Germany, 2011, http://link.springer.com/ chapter/10.1007\%2F978-3-642-16657-0_7\#page-1.

[5] P. Mondal, Nanomechanical properties of cementitious materials [Doctoral thesis], Northwestern University, 2008.
[6] R. J. Myers, S. A. Bernal, R. San Nicolas, and J. L. Provis, "Generalized structural description of calcium-sodium aluminosilicate hydrate gels: the cross-linked substituted tobermorite model," Langmuir, vol. 29, no. 17, pp. 5294-5306, 2013.

[7] E. R. Ylmén, Early hydration of portland cement-an infrared spectroscopy perspective complemented by calorimetry and scanning electron microscopy [Ph.D. thesis], Chalmers University of Technology, Gothenburg, Sweden, 2013.

[8] B. Han, X. Yu, and J. Ou, "Multifunctional and smart carbon nanotube reinforced cement-based materials," in Nanotechnology in Civil Infrastructure: A Paradigm Shift, K. Gopalakrishnan, B. Birgisson, P. Taylor, and N. O. Attoh-Okine, Eds., pp. 1-47, Springer, Berlin, Germany, 2011.

[9] L. Raki, J. Beaudoin, R. Alizadeh, J. Makar, and T. Sato, "Cement and concrete nanoscience and nanotechnology," Materials, vol. 3, no. 2, pp. 918-942, 2010.

[10] R. Panneer Selvam, K. D. Hall, V. J. Subramani, and S. J. Murray, "Application of nanoscience modeling to understand the atomic structure of C-S-H," in Nanotechnology in Civil Infrastructure a Paradigm Shift, K. Gopalakrishnan, Ed., pp. 87-102, Springer, Berlin, Germany, 2011.

[11] J. Makar, "The effect of SWCNT and other nanomaterials on cement hydration and reinforcement," in Nanotechnology in Civil Infrastructure, K. Gopalakrishnan, B. Birgisson, P. Taylor, and N. O. Attoh-Okine, Eds., pp. 103-130, Springer, Berlin, Germany, 2011.

[12] M. Kutschera, L. Nicoleau, and M. Bräu, "Nano-optimized construction materials by nano-seeding and crystallization control," in Nanotechnology in Civil Infrastructure, K. Gopalakrishnan, B. Birgisson, P. Taylor, and N. O. Attoh-Okine, Eds., pp. 175-205, Springer, Berlin, Germany, 2011.

[13] B. Bhuvaneshwari, S. Sasmal, and N. R. Iyer, "Nanoscience to nanotechnology for civil engineering-proof of concepts," in Proceedings of the 4th WSEAS International Conference on 
Recent Researches in Geography, Geology, Energy, Environment and Biomedicine (GEMESED '11), 2011, http://www.wseas.us/ e-library/conferences/2011/Corfu/GEMESED/GEMESED-40 .pdf.

[14] K. L. Scrivener, "Nanotechnology and cementitious materials," in Nanotechnology in Construction 3: Proceedings of the NICOM3, Z. Bittnar, P. J. M. Bartos, J. Němeček, V. Smilauer, and J. Zeman, Eds., pp. 37-42, Springer, Berlin, Germany, 2009.

[15] E. J. Garboczi, "Concrete nanoscience and nanotechnology: definitions and applications," in Nanotechnology in Construction 3: Proceedings of the NICOM3, Z. Bittnar, P. J. M. Bartos, J. Němeček, V. Šmilauer, and J. Zeman, Eds., pp. 81-88, Springer, Berlin, Germany, 2009.

[16] H. Li, H. Xiao, J. Yuan, and J. Ou, "Microstructure of cement mortar with nano-particles," Composites B, vol. 35, no. 2, pp. 185-189, 2004.

[17] B. Jo, J. Choi, and S. Kang, "An experimental study on the characteristics of chemically synthesized nano-cement for carbon dioxide reduction," Advanced Materials Research, vol. 148-149, pp. 1717-1721, 2011.

[18] KSL 5110: 2001, "Testing method for specific gravity of hydraulic cement," Bureau of Korean standard, Seoul, Republic of Korea, 2006.

[19] KSL 5108: 2007, “Testing method for setting time of hydraulic cement by vicat needle," Bureau of Korean standard, Seoul, South Korea, 2007.

[20] KSF 2405, "Testing method for compressive strength of concrete," Seoul, South Korea, Bureau of Korean Standard, 2010.

[21] B. Jo, J. Choi, and S. Kang, "An experimental study on the characteristics of chemically synthesized nanocement for carbon dioxide reduction," Journal of Ceramic Processing Research, vol. 12, no. 3, pp. 294-298, 2011.

[22] S. Chakraborty, S. P. Kundu, A. Roy, B. Adhikari, and S. B. Majumder, "Effect of jute as fiber reinforcement controlling the hydration characteristics of cement matrix," Industrial and Engineering Chemistry Research, vol. 52, no. 3, pp. 1252-1260, 2013.

[23] B.-W. Jo, S. Chakraborty, and K. W. Yoon, "A hypothetical model based on effectiveness of combined alkali and polymer latex modified jute fibre in controlling the setting and hydration behaviour of cement," Construction and Building Materials, vol. 68, pp. 1-9, 2014.

[24] KSL 5201: 2013, “Portland cement," Bureau of Korean standard, Seoul, South Korea, 2013.

[25] E. H. kim, Understanding effects of silicon/aluminum ratio and calcium hydroxide on chemical composition, Nanostructure and compressive strength for metakaolin geopolymers [M.S. thesis], University of Illinois, Urbana-Champaign, Ill, USA, 2012, https://www.ideals.illinois.edu/bitstream/handle/2142/34257/ Kim_Eric.pdf? sequence $=1$.

[26] M. Sathupunya, E. Gulari, and S. Wongkasemjit, "ANA and GIS zeolite synthesis directly from alumatrane and silatrane by solgel process and microwave technique," Journal of the European Ceramic Society, vol. 22, no. 13, pp. 2305-2314, 2002.

[27] J. Byung-Wan, S. Chakraborty, K. Heon Kim, and Y. Sung Lee, "Effectiveness of the top-down nanotechnology in the production of ultrafine cement $(\sim 220 \mathrm{~nm})$," Journal of Nanomaterials, vol. 2014, Article ID 131627, 9 pages, 2014.

[28] M. J. Gibbs, " $\mathrm{CO}_{2}$ emissions from cement production. Good Practice Guidance and Uncertainty Management in National Greenhouse Gas Inventories, Industrial 182 Processes
Sector," http://www.ipcc-nggip.iges.or.jp/public/gp/bgp/3_1_ Cement_Production.pdf.

[29] Cement Raw Materials, British Geological Survey Mineral Profile, Natural Environmental Research Council, Office of the Deputy Prime Minister, 2005, http://www.scribd.com/doc/ 217671476/comm-profile-cement-pdf. 

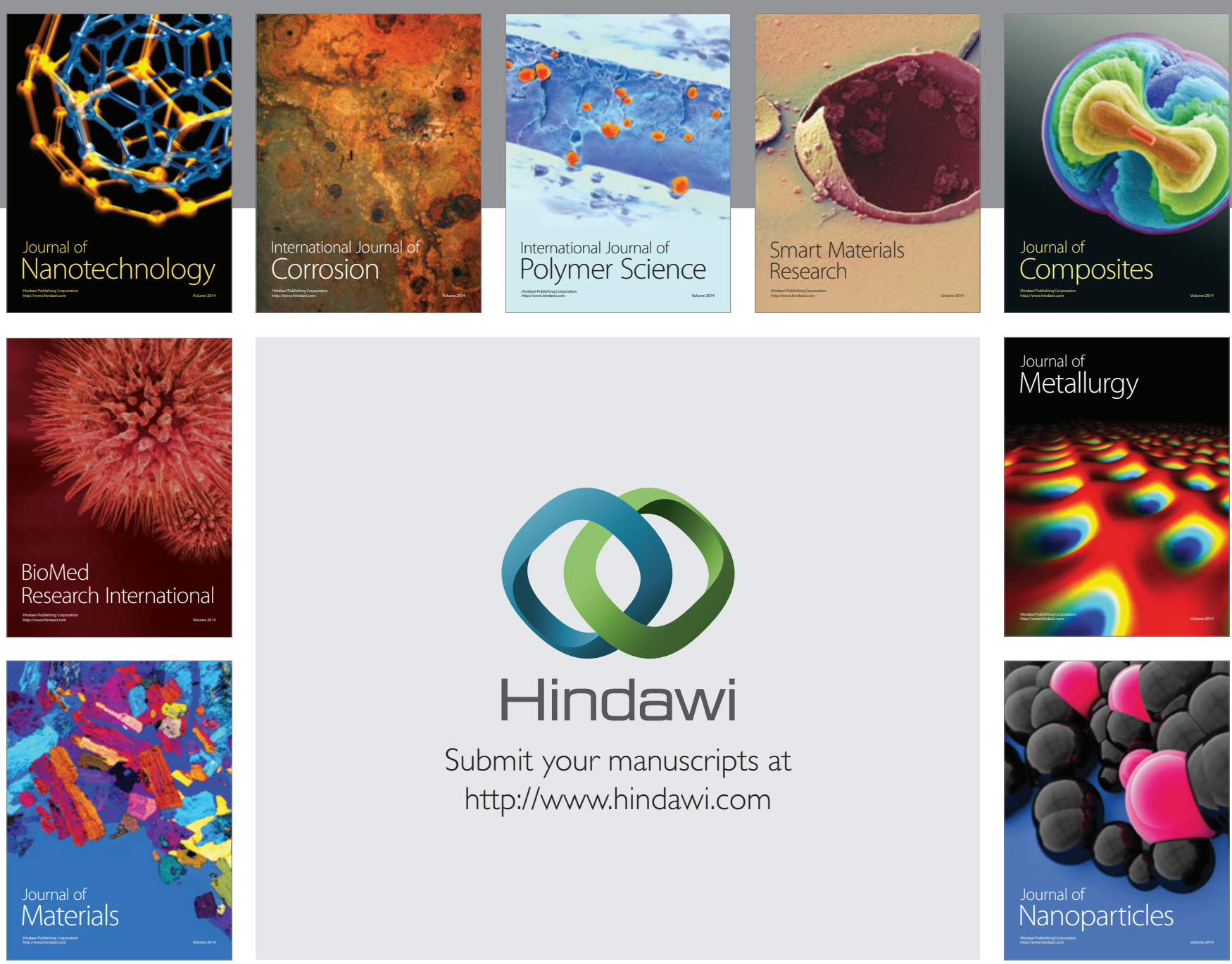

Submit your manuscripts at http://www.hindawi.com
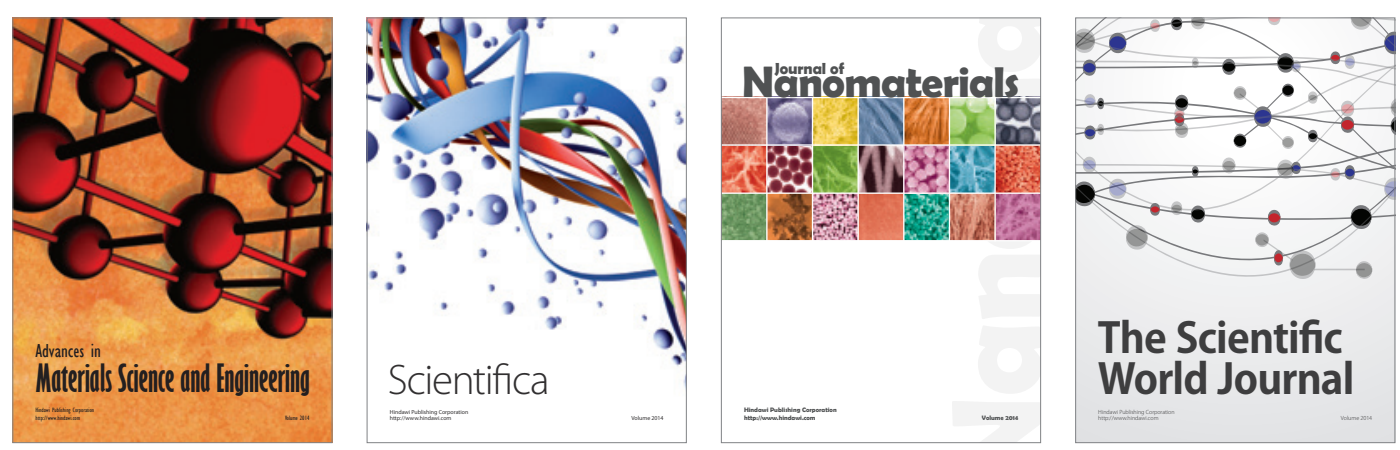

\section{The Scientific World Journal}
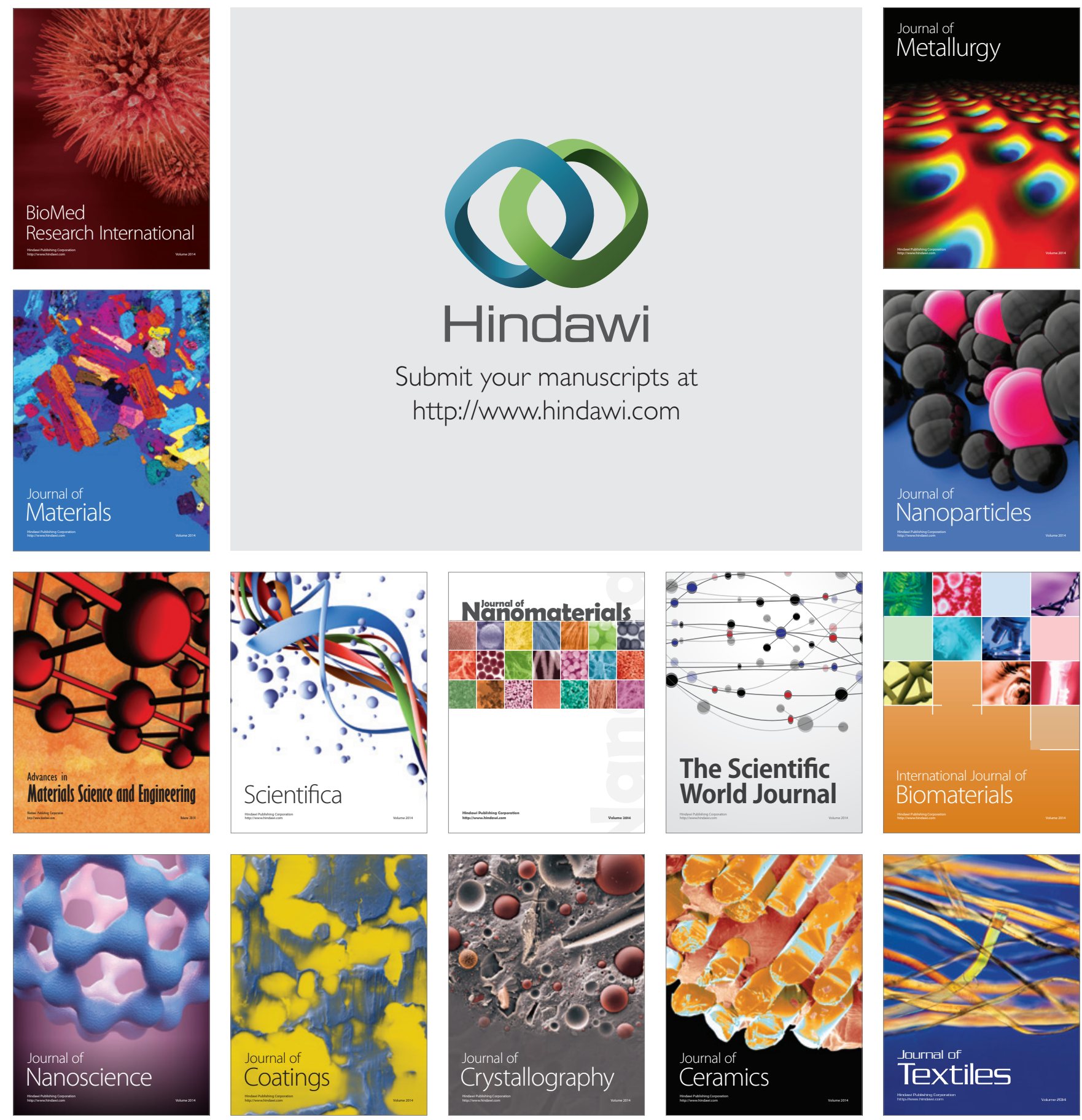